\title{
Video-urodynamic Improvement of Trigonal BTX-A Injection for Patients with Poor Bladder Compliance Secondary to Spinal Cord Injury
}

\author{
Jiang Zhuocheng ${ }^{2}$, Chen Hui ${ }^{1,3, *}$, Yang $\mathrm{XH}^{1}$, Huang $\mathrm{MP}^{1}$, Huang $\mathrm{TH}^{1}$, Liu $\mathrm{QL}^{1}, \mathrm{Li} \mathrm{QQ}^{1}$, \\ Yang $\mathrm{XY}^{1}$, Xiao $\mathrm{XH}^{1}$, Liu $\mathrm{J}^{1}$, Xie Keji ${ }^{4}$, Jiang Chonghe ${ }^{3}$ \\ ${ }^{1}$ Department of Urology, Guangdong Provincial Work Injury Rehabilitation Hospital and Jinan University, Guangzhou, China \\ ${ }^{2}$ Department of Surgery, the Second People's Hospital of Baiyun District, Guangzhou, China \\ ${ }^{3}$ Department of Urology, Qingyan City People's Hospital, Jinan University, Guangdong, China \\ ${ }^{4}$ Department of Urology, Guangzhou First Municipal People’s Hospital, Guangzhou, China \\ *Corresponding author: doc.chenhui@163.com
}

\begin{abstract}
Objective: To evaluate video-urodynamic improvement for trigonal BTX-A injection in patients with neurological poor bladder compliance. Methods: 68 consecutive inpatients with poor bladder compliance secondary to spinal cord injury(SCI) received trigonal injections of BTX-A(300U) into the bladder from June 2014 to February 2017. All were evaluated video-urodynamic outcome included detrusor leak point pressure (DLPP), bladder compliance (BC) and vesicoureteral reflux (VUR) at baseline and 12 weeks post-injection. Results: all outcomes improved significantly compared to baseline. The improvement percentage of DLPP (44.36\%) and BC (77.13\%). No patient developed unilateral or bilateral VUR. Conclusions: Trigone-including BTX-A injection is safe and effective as the treatment for low BC and does not induce VUR.
\end{abstract}

Keywords: video-urodynamic, bladder trigone, botulinum toxin A, low bladder compliance, spinal cord injury

Cite This Article: Jiang Zhuocheng, Chen Hui, Yang XH, Huang MP, Huang TH, Liu QL, Li QQ, Yang XY, Xiao XH, Liu J, Xie Keji, and Jiang Chonghe, "Video-urodynamic Improvement of Trigonal BTX-A Injection for Patients with Poor Bladder Compliance Secondary to Spinal Cord Injury.” American Journal of Medical Case Reports, vol. 6, no. 1 (2018): 15-17. doi: 10.12691/ajmcr-6-1-5.

\section{Introduction}

Detrusor leak point pressure (DLPP) is characterized by the lowest value of detrusor pressure at which leakage is observed in the absence of abdominal strain or detrusor contraction [1]. Sustained DLPP is the most important risk factor for the function of upper urinary tract in patients with neuro-urological disorders, such as stroke, brain diseases and chronic spinal cord injury (SCI) [2]. Therefore, keeping the DLPP within safe limits has become a primary treatment goal for SCI patients [3].

Botulinum toxin A (Botox ${ }^{\circledR}$, Allergan, Irvine, Calif.) is recommended as the second-line treatment for those patients who have an inadequate response to or are intolerant to anticholinergic medication $[4,5]$. In the past ten years, intradetrusor injection of BTX-A was performed while avoiding the trigone to prevent VUR. To our knowledge, several studies reported satisfactory clinical results about combined detrusor-trigone BTX-A injections [6-12]. However, most of these studies were small and single-center experience. Therefore, encouraged by our satisfactory clinical effects, we performed this study to evaluate the efficacy and safety of combined detrusor-trigone BTX-A injections for patients with poor bladder compliance secondary to spinal cord injury (SCI).

\section{Materials and Methods}

Consecutive SCI inpatients with poor bladder compliance $\left(<20 \mathrm{ml} / \mathrm{cmH}_{2} \mathrm{O}\right)$ [1] were recruited in this trail from June 2014 to February 2017. Inserted A 23 gauge approximately $2 \mathrm{~mm}$ into the detrusor under local anesthesia or epidural anesthesia in the operating room. $300 \mathrm{U}^{\text {Botox }}{ }^{\circledR}$ vials (100 $\mathrm{U}$ each) were reconstituted in a total of $30 \mathrm{ml}$ sterile saline. Administer 24 injection sites into the bladder wall while 6 sites into the bladder trigone sparing a $5 \mathrm{~mm}$ distance to the vicinity of the ureteral orifices and the bladder neck (Figure 1). A16 Foley catheter had been inserted for 3-5 days after injection. The outcomes were the changes in the videourodynamic test evaluated at baseline, and at 12 weeks after injection: (1) incidence of vesicoureteral reflux (VUR); (2) detrusor leak point pressure (DLPP); (3) bladder compliance (BC). The related adverse events were collected. The study was approved by the ethics committees and patients provided written informed consent before injection.

Pair Student's t-test was used for comparison of DLPP, $\mathrm{BC}$ and results are presented as means \pm standard deviation. The chi-square test was used for categorical data. A P value of 0.05 or less was considered statistically significant. Statistical analyses were performed with SPSS 13.0 software (SPSS, Inc., Chicago, IL). 


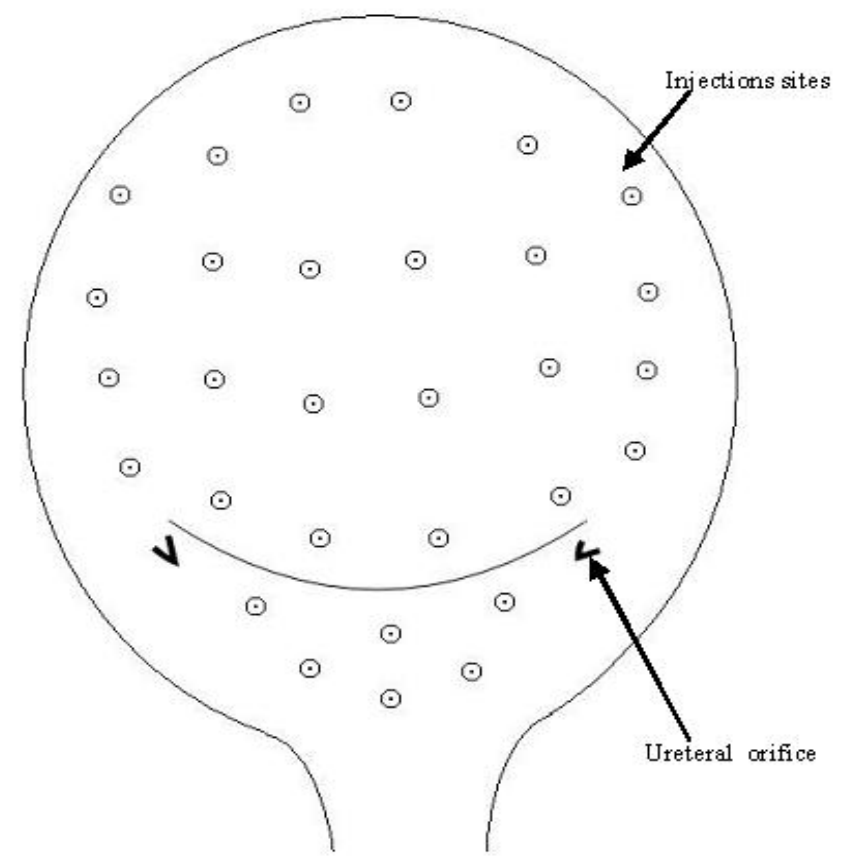

Figure 1. Location of BTX-A injection

\section{Results}

A total of 68 inpatients (55 male and 13 female) were enrolled in this trail. Patients' mean age, mean weight, duration of injury were $38.81 \mathrm{y}, 50.24 \mathrm{~kg}, 10.19$ months, respectively. 59 patients were AIS grade A, and other 9 AIS grade B (Table 1).

Table 1. Baseline characteristics of the participants

\begin{tabular}{lc}
\hline Characteristic & Number of patients $(\mathrm{N}=41)$ \\
\hline Age, yr, mean (SD) & $30.81(16.59)$ \\
Gender, men, $\mathrm{n}(\%)$ & $55(80.88)$ \\
Weight, kg, mean (SD) & $51.24(20.66)$ \\
Duration of injury, months, mean (SD) & $10.19(9.17)$ \\
AIS grade, A/B, n & $59 / 9$ \\
\hline
\end{tabular}

AIS = the American social injury association.

No patient developed unilateral or bilateral VUR at week 12. Compared the baseline data, significant difference were present by week 12 for DLPP $\left(51.48 \mathrm{cmH}_{2} \mathrm{O}\right.$ vs. $\left.28.64 \mathrm{~cm} \mathrm{H} \mathrm{H}_{2} \mathrm{O}, \mathrm{P}<0.001\right)$ and $\mathrm{BC}\left(5.16 \mathrm{ml} / \mathrm{cmH}_{2} \mathrm{O}\right.$ vs. $9.14 \mathrm{ml} / \mathrm{cm} \mathrm{H}_{2} \mathrm{O}, \mathrm{P}<0.001$ ) (Figure 2). None of patients reported adverse events, such as nausea, vomiting, weakness in the respiratory.

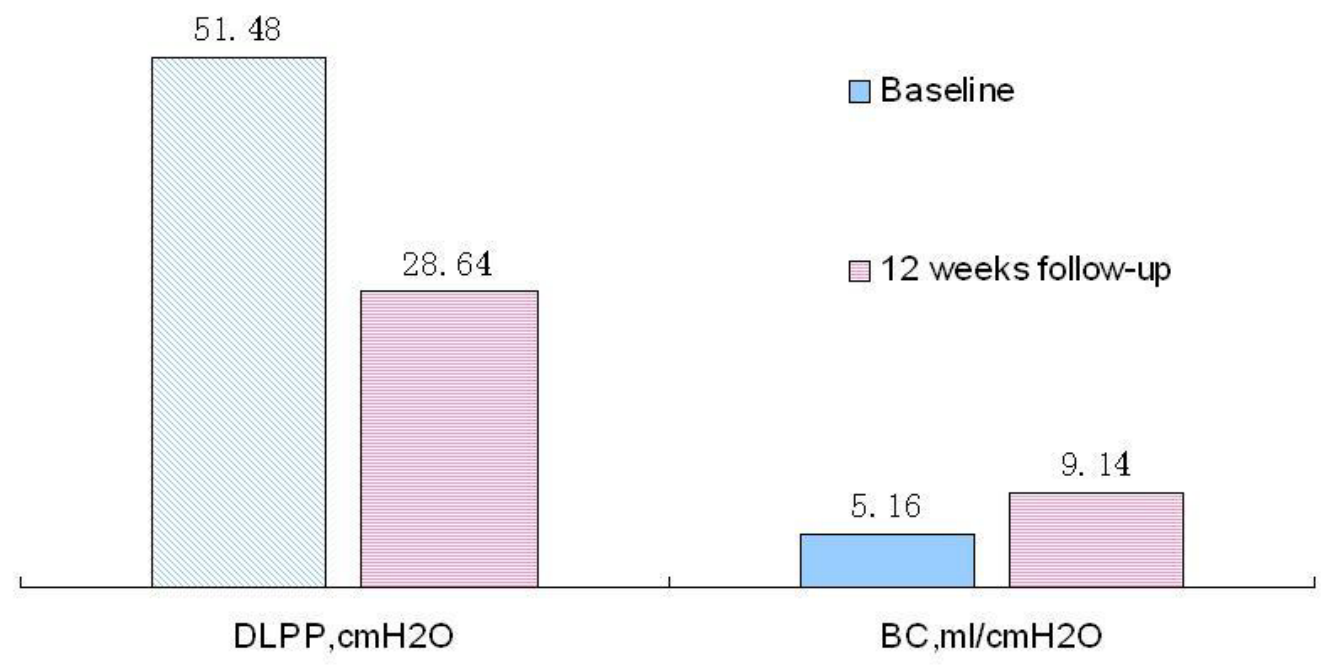

Figure 2. Videourodynamic parameters of patients at baseline and 12 weeks follow-up

\section{Discussion}

Our study demonstrates that trigonal BTX-A injection does not induce VUR during the 12 week follow-up after injection. We also noticed our results similar to the preview studies [6-12]. One study found that not one of their 24 adults with $\mathrm{OAB}$ refractory to anticholinergic treatment who received trigoneinjection of BTX-A developed VUR during at 6-month follow-up [6]. A similar result was obtained in 10 women 6 weeks after treatment [7]. Interestingly, Kuo [8] found that the degree of renal hydronephrosis decreased with treatment in four of the five patients with baseline hydronephosis after injection. Another study [9] also confirmed the safety of trigone injections of BTX-A in terms of development of VUR because the only patient in their series with VUR previous to theinjection had it cured after BTX-A injection. Trigonal BTX-Ainjection has been proven effective in adults with neurological or non-neurological disorders.
According to the guideline, keeping the DLPP within lower limits has become a primary treatment goal for Low $\mathrm{BC}$ [3]. The present trial reports significant improvements in these parameters were evident with the 300-U dose of BTX-A injection. It is reported that abundant sensory nerve fibers are particularly dense in bladder trigone, and smooth muscle of bladder trigone is sensitive to small pressure changes [24]. According to these studies, combined detrusor trigone BTX-A injections may help desensitize the bladder and thereby help to decrease detrusor pressure.

No patients developed systemic or significant adverse events of treatment in this trial.

A limitation of this study is that number of patients was relatively fewer. Therefore, further studies are warranted.

\section{Conclusions}

Trigone-including BTX-A injection is safe and effective as the treatment for low BC and does not induce VUR. 


\section{Acknowledgments}

This study was supported by Medical Scientific Research Foundation of Guangdong Province, China (grant number B2017040).

\section{Conflict of Interest Statement}

The authors declare no conflict of interest.

\section{References}

[1] Stöhrer M, Goepel M, Kondo A, et al. The standardization of terminology in neurogenic lower urinary tract dysfunction: with suggestions for diagnostic procedures. International Continence Society Standardization Committee. Neurourol Urodyn. 1999; 18(2): 139-158.

[2] Gerridzen RG, Thijssen AM, Dehoux E, et al. Risk factors for upper tract deterioration in chronic spinal cord injury patients. $\mathrm{J}$ Urol, 1992. 147(2): 416-8.

[3] Stöhrer M, Blok B, Castro-Diaz D, et al. EAU guidelines on neurogenic lower urinary tract dysfunction. Eur Urol, 2009, 56(1): 81-88

[4] Marte A. Onabotulinumtoxin A for Treating Overactive/Poor Compliant Bladders in Children and Adolescents with Neurogenic Bladder Secondary to Myelomeningocele. Toxins 2013; 5(1): 16-24.

[5] Schurch B, de Sèze M, Denys $P$,et al. Botulinum toxin type a is a safe and effective treatment for neurogenic urinary incontinence: results of a single treatment, randomized, placebo controlled 6month study. J Urol, 2005. 174(1): 196-200.

[6] Huang $M$, Chen $H$, Jiang $C$, et al. Effects of botulinum toxin A injections in spinal cord injury patients with detrusor overactivity and detrusor sphincter dyssynergia. J RehabilMed. 2016; 48(8): 683-687.

[7] Citeri M, Spinelli M, Zanollo L, et al. Botulinum toxin into the trigone in neurogenic overactive bladder non-responder to detrusor injection. Eur Urol Suppl 2008; 7: 213.

[8] Kuo HC. Bladder base/trigone injection is safe and as effective as bladder body injection of onabotulinumtoxin A for idiopathic detrusor overactivity refractory to antimuscarinics. Neurourol Urodyn 2011; 30: 1242-1248.

[9] Pinto R, Lopes T, Frias B, Silva JA, Silva CM, Cruz C et al. Trigonal injection of botulinum toxin $\mathrm{A}$ in patients with refractory bladder pain syndrome/interstitial cystitis. Eur Urol 2010; 58: 360-365.
[10] Hui C, Keji X, Chonghe J, et al. Combined detrusor-trigone BTX-A injections for urinary incontinence secondary to neurogenic detrusor overactivity. Spinal Cord. 2016; 54(1): 46-50.

[11] Manecksha RP, Cullen IM, Ahmad S, McNeill G, Flynn R, McDermott TE et al. Prospective randomised controlled trial comparing trigone-sparing versus trigone-including intradetrusor injection of abobotulinumtoxin A for refractory idiopathic detrusor overactivity. Eur Urol 2012; 61: 928-935.

[12] Conte A, Giannantoni A, Gubbiotti M, et al. Intradetrusorial Botulinum Toxin in Patients with Multiple Sclerosis: A Neurophysiological Study. Toxins.2015; 7(9): 3424-3435.

[13] Patrick DL, Martin ML, Bushnell DM, et al. Quality of life of women with urinary incontinence: further development of the incontinence quality of life instru ment (I-QOL). Urology19 99; 53:71-76.

[14] Del Popolo G. Neurogenic detrusor overactivity treated with english botulinum toxin a: 8-year experience of one single centre. Eur Urol, 2008. 53(5): p. 1013-19.

[15] Cruz F. Efficacy and safety of onabotulinumtoxinA in patients with urinary incontinence due to neurogenic detrusor overactivity: a randomised, double-blind, placebo-controlled trial. Eur Urol, 2011. 60(4): p. 742-50.

[16] Ginsberg D. Phase 3 efficacy and tolerability study of onabotulinumtoxin A for urinary incontinence from neurogenic detrusor overactivity. J Urol, 2012. 187(6): p. 2131-9.

[17] Grosse J. Success of repeat detrusor injections of botulinum a toxin in patients with severe neurogenic detrusor overactivity and incontinence. Eur Urol, 2005. 47(5): p.653-9.

[18] Stöhrer M. Diagnosis and treatment of bladder dysfunction in spinal cord injury patients. Eur Urol Update Series 1994. 3: p. $170-5$.

[19] Castro-Diaz D. Surgery for the neuropathic patient. In Incontinence, P. Abrams, et al., Editors. 2002, Health Publication: Plymouth. p. 865-891.

[20] Frankel HL. Long-term survival in spinal cord injury: a fifty year investigation. Spinal Cord, 1998. 36(4): p. 266-74.

[21] Jamil F. Towards a catheter free status in neurogenic bladde dysfunction: a review of bladder management options in spinal cord injury (SCI). Spinal Cord, 2001. 39(7): p. 355-61.

[22] Schurch B, Stöhrer M, Kramer G, et al. Botulinum-A toxin for treating detrusor hyperreflexia in spinal cord injured patients: a new alternative to anticholinergic drugs? Preliminary results. J Urol, 2000, 164 (3 Pt 1):692-697.

[23] Cohen BL, Barboglio P, Rodriguez D, et al. Preliminary results of a dose-finding study for botulinum toxin-A in patients with idiopathic overactive bladder: 100 versus 150 units. Neurourol Urodyn 2009; 28 (3 Pt 1): 205-8.

[24] Klein LA. Urge incontinence can be a disease of bladder sensors. J Urol 1988; 139(5): 1010-1014. 